\title{
Reducing the Thermal Inhomogeneity of Massive Steel Slabs in Continuous Furnaces
}

\author{
G. M. Druzhinin ${ }^{a}$, Yu. A. Samoilovich ${ }^{b}$, and E. V. Popov \\ ${ }^{a}$ Research Institute of Metallurgical Thermal Engineering \\ ${ }^{b}$ Ural Federal University \\ Received January 15, 2013
}

\begin{abstract}
A method is proposed for selecting the best displacement parameters for supporting pipes. The influence of lateral displacement of the longitudinal guide pipes in continuous furnaces on the disappearance of the dark spot is studied.
\end{abstract}

Keywords: supporting pipe, mathematical model, push-rod furnace, thermal heterogeneity, lateral pipe displacement

DOI: $10.3103 / \mathrm{S} 096709121307005 \mathrm{X}$

When metal moves in a continuous furnace with a lower heating zone, the screening of the billet by hearth equipment (guide pipes, riders) leads to the formation of low-temperature zones (dark spots) on the billet. The associated thermal inhomogeneity of the billet leads to overloading of the mill rollers and the appearance of defects in the final product. Numerous experiments indicate that, for low- and moderate-carbon steel, the permissible temperature variation $\Delta T$ is $50-60^{\circ} \mathrm{C}$. Otherwise, defects are likely to form in the steel.

The thermal heterogeneity is assessed in terms of the temperature difference in the contact zone of the lower billet surface with the guide pipes and in the plane between adjacent guide pipes.

The thermal heterogeneity of the billet may be reduced by lateral displacement of the hearth pipes to a region of the furnace adjacent to the monolithic hearth.

Very few results have been published regarding the influence of supporting-pipe displacement on the thermal heterogeneity of heated billet. In the continuous push-rod furnace at the 2000 mill in OAO Novolipetskii Metallurgicheskii Kombinat (NLMK), the guide pipes were displaced starting at the middle of the second welding zone (Fig. 1), as described in [1]. The maximum displacement $\Delta S$, corresponding to the boundary with the monolithic hearth, is $300 \mathrm{~mm}$.

The following data were presented in [1]:

(1) at $260 \mathrm{t} / \mathrm{h}$, the temperature difference is $33^{\circ} \mathrm{C}$ without displacement and $12^{\circ} \mathrm{C}$ with pipe displacement;

(2) at $300 \mathrm{t} / \mathrm{h}$, the temperature difference is $31^{\circ} \mathrm{C}$ without displacement and $8^{\circ} \mathrm{C}$ with pipe displacement.
This significant effect is easy to explain. With displacement of the supporting pipe, the cool surface section of the billet in contact with the pipe (or rider) is exposed to the heating gases, and the dark spot gradually disappears.

Temperature measurements at the surface of steel strip supplied to the finishing group of a broad-strip mill after heating steel slab (thickness $260 \mathrm{~mm}$ ) in a continuous furnace of the same type as the furnace at the OAO NLMK 2000 mill (according to Krupp Stahl data) were reported in [2]. It follows from the experimental data that displacement of the guide pipes reduces the temperature difference over the length of the strip from 38 to $25^{\circ} \mathrm{C}$.

The rate of elimination of the dark spots depends on factors such as the billet thickness, the thermal conductivity of the heated metal, the furnace productivity, and the length of the furnace sections with displacement of the supporting pipes. In the reconstruction of continuous furnaces, the displacement parameters are selected on the basis of practical experience.

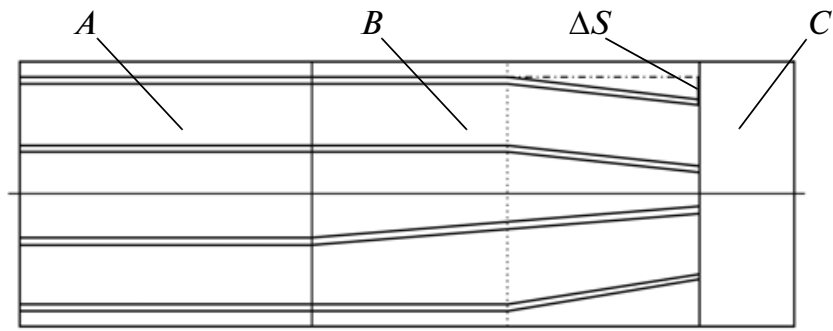

Fig. 1. Lateral displacement of supporting pipes in a continuous furnace: $(A)$ continuous zone; $(B)$ welding zone; (C) soaking zone; $\Delta S$, displacement of hearth pipes. 


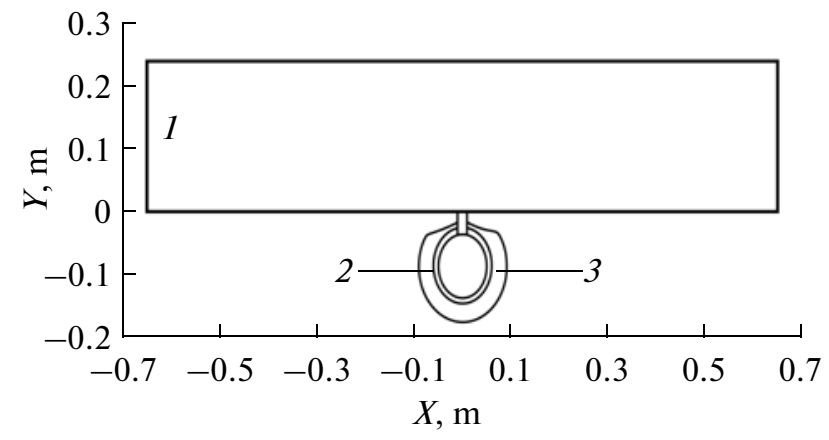

Fig. 2. Calculated section of slab-pipe system: (1) calculated section of slab; (2) water-cooled steel pipe; (3) fireclay heat-insulating pipe.

In the present work, we outline a method of selecting the displacement configuration by simulation of billet heating in a continuous furnace of push-rod type.

The goal of the calculation is to select two basic parameters: the section of the furnace where displacement must begin $L_{N}$; and the required displacement $\Delta S$. These parameters are determined by successive approximation, with monitoring of the billet's thermal heterogeneity.

We assume that the billet moves at constant speed $V=L / t_{k}$ in the furnace's working space. Here $L$ is the length of the furnace's useful hearth, $\mathrm{m} ; t_{k}$ is the total duration of billet heating in the furnace, $s$.

As an example, we consider slab heating in a pushrod furnace corresponding to that at the OAO NLMK 2000 mill. In that case, the displacement of the supporting pipe begins at the midpoint of the second welding zone in the furnace, according to [1]. Calculation of the displacement parameters reduces to the following operations.

The starting point is the temperature field of the hot slab without displacement, which is determined on the basis of mathematical simulation by the finiteelement method, with solution of the nonlinear heatconduction equation

$$
\rho C \frac{\partial T}{\partial t}=\operatorname{div}(\lambda \operatorname{grad} T)+Q(x, y, z, t)
$$

In the solution, we take account of the initial condition: $T\left(t_{0}\right)=T_{\text {in }}$ at $t=0$. We also employ the following boundary conditions at the billet surface

$$
\pm\left.\lambda \frac{\partial T}{\partial n}\right|_{\text {sur }}=\alpha_{k}\left(T_{\text {sur }}-T_{S}\right)+\sigma_{\mathrm{B}}\left(T_{\text {sur }}^{4}-T_{S}^{4}\right)
$$

where $T$ is the temperature; $t$ is the time; $\lambda$ is the thermal conductivity; $\rho$ is the density; $C$ is the specific heat of the metal (calculated in accordance with [3]); $Q$ is the bulk heat-source density associated with phase transformation; $\sigma_{\mathrm{B}}$ is the radiant heat-transfer coefficient; $\alpha_{k}$ is the convective heat-transfer coefficient to the slab surface; $T_{S}$ is the temperature of the heating gas; $T_{\text {in }}$ is the initial slab temperature; $n$ is the normal to the slab surface.

With increase in temperature to $580-620^{\circ} \mathrm{C}$, the initial pearlite structure of the carbon steel is converted to austenite structure, with the release of heat $L$, $\mathrm{kJ} / \mathrm{kg}$. The heat liberation in the pearlite $P \rightarrow A$ austenite transformation is taken into account by specifying the heat-source density in the form

$$
Q=\rho L \frac{\partial \Psi}{\partial t}
$$

where $\Psi=\Psi(x, y, t)$ is the proportion of transformed austenite.

The heat-conduction problem is solved with specified initial condition $T_{\text {in }}=f(x, y, t)$ and also with specified temperature $T_{S}^{j}(j)$ of the heating gas in the upper and lower furnace zones, where $j=1,2,3, \ldots$ is the number of the corresponding upper and lower furnace zones.

Simulation involves solution of the heat-conduction problem for the slab and a section of the supporting pipe, whose external surface is heat-insulated so as to reduce losses. The model takes account of the temperature dependence of the steel's basic thermophysical properties: the thermal conductivity and specific heat.

If we take account of two spatial measurements ( $x$ and $y$; Fig. 2), we may write the heat-conduction equation in the form

$$
\rho C_{p} \frac{\partial T}{\partial y}=\frac{\partial}{\partial x}\left(\lambda \frac{\partial T}{\partial x}\right)+\frac{\partial}{\partial y}\left(\lambda \frac{\partial T}{\partial y}\right)+\rho L \frac{\partial \Psi}{\partial t} .
$$

The boundary conditions adopted are as follows.

(1) For the slab's upper surface

$$
\lambda \frac{\partial T}{\partial y}=\sigma_{\mathrm{Br}}\left[\left(\frac{T_{S}}{100}\right)^{4}-\left(\frac{T_{m}}{100}\right)^{4}\right],
$$

where $\sigma_{\mathrm{Br}}$ is the reduced radiant heat-transfer coefficient, $\mathrm{W} /\left(\mathrm{m}^{2} \mathrm{~K}^{4}\right) ; T_{m}$ is the temperature at the metal's upper surface. We adopt the standard form of $\sigma_{\mathrm{Br}}$ recommended in the analysis of heat transfer in a multizone continuous furnace of push-rod type [4].

(2) For the boundary surfaces at the calculated section $(x= \pm 0.65 \mathrm{~m})$, the heat-insulation condition

$$
\frac{\partial T}{\partial x}=0
$$

(3) For the guide pipes, an equation of convective type taking account of the intense cooling of the pipe's inner surface by a flux of water or vapor-air mixture (depending on the cooling method employed)

$$
-\lambda \frac{\partial T}{\partial r}=\alpha_{k}\left(T-T_{k}\right)
$$


where $T_{k}$ is the temperature of the cooling medium (water or vapor-air mixture): $T$ is the temperature of the cooled pipe surface; $\alpha_{k}$ is the convective heattransfer coefficient; $r$ is the radius of the internal pipe surface.

(4) For the outer surface of the guide pipe, a formula for the heat-flux density

$$
\lambda \frac{\partial T}{\partial y}=\varepsilon_{T} \sigma_{0}\left(T_{S}^{4}-T_{T}^{4}\right)-\varepsilon_{T} \varepsilon_{m} \sigma_{0} \varphi_{T}\left(T_{S}^{4}-T_{m}^{4}\right),
$$

where $\varepsilon_{T}$ is the emissivity of the pipe's outer surface; $\varepsilon_{m}$ is the emissivity of the metal; $\varphi_{T}$ is an angular coefficient taking account of the reradiation to the pipe surface from the lower surface of the slab [4]; $\sigma_{0}$ is the emissivity of an absolutely black body; $T_{T}$ is the temperature of the guide pipe's outer surface.

(5) For the lower slab surface, a formula for the heat-flux density [5]

$$
\lambda \frac{\partial T}{\partial y}=\varepsilon_{T} \sigma_{0}\left(T_{S}^{4}-T_{T}^{4}\right)-\frac{\varepsilon_{T} \varepsilon_{m} \sigma_{0}}{1+\left(\frac{x}{R}\right)^{2}}\left(T_{S}^{4}-T_{M}^{4}\right) .
$$

Here $T_{S}, T_{m}$, and $T_{T}$ are the temperatures of the hot gas, the lower slab surface, and the guide pipe's outer surface; $2 R$ is the external diameter of the heat insulation on the guide pipes; $\varepsilon_{p}$ is the equivalent emissivity, depending on the temperature of the heating gas and the metal surface [6]

$$
\varepsilon_{p}=1.06-0.34 T_{S}^{\prime}-0.27 T_{m}^{\prime}+0.1 T_{S}^{\prime} T_{m}^{\prime},
$$

where

$$
T_{S}^{\prime}=\frac{T_{S}}{1000} ; T_{m}^{\prime}=\frac{T_{m}}{1000} .
$$

As a result of calculating the temperature field of the slab, without pipe displacement, we determine the slab-heating time $t_{k}$ and the distribution of the temperature $T$ over its cross section, with two final conditions

$$
T_{\text {sur }}=T_{\text {sur }}^{\mathrm{f}} ; \Delta T=\Delta T^{\mathrm{f}},
$$

where $T_{\text {sur }}^{\mathrm{f}}$ and $\Delta T^{\mathrm{f}}$ are specified values of the temperature at the slab's upper surface and the temperature difference over its cross section. Knowing the total slab-heating time $t_{k}$ and the length $L$ of the furnace's useful hearth, we may calculate the time $t_{N}$ corresponding to the onset of pipe displacement

$$
t_{N}=t_{k} \frac{L_{N}}{L},
$$

where $L_{N}$ is the distance from the billet's point of entry in the furnace to the section where displacement of the supporting pipes begins (the initial position).

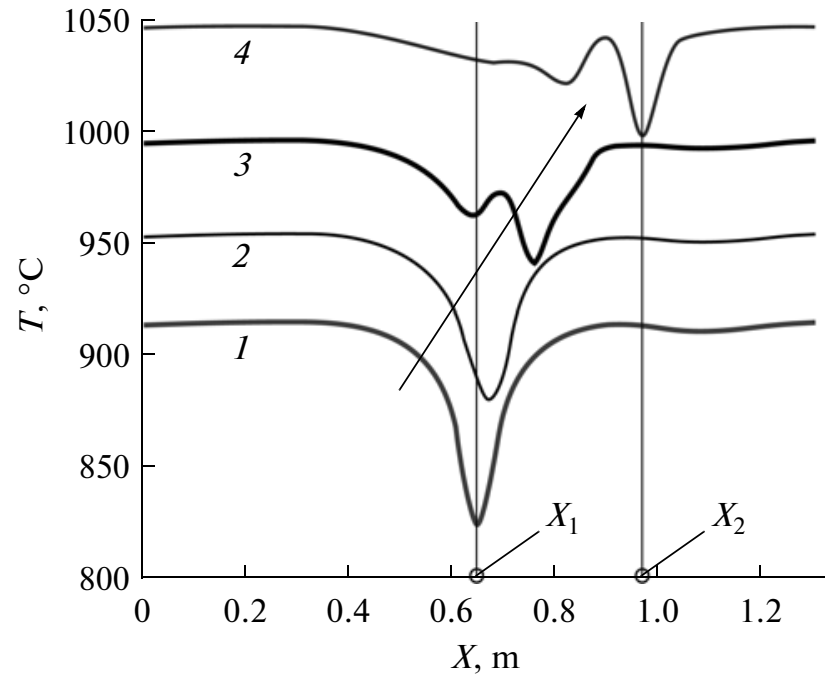

Fig. 3. Temperature distribution along the lower slab surface with pipe displacement at $8000 \mathrm{~s}(1), 8500 \mathrm{~s}$ (2), $9100 \mathrm{~s}(3)$, and $10000 \mathrm{~s} \mathrm{(4).}$ mula

The pipe displacement is calculated from the for-

$$
S(t)=K\left(t-t_{N}\right),
$$

where $K$ is the displacement-rate coefficient

$$
K=\frac{\Delta S}{t_{K}-t_{N}} .
$$

Introducing the displacement $S(t)$ in the algorithm for determining the thermal conductivity, we may determine the temperature field in the heated slab with displacement of the supporting pipes.

In particular, if $L=38 \mathrm{~m}, L_{N}=32.1 \mathrm{~m}$, and $\Delta S=$ $0.32 \mathrm{~m}$, we find from Eqs. (11) and (13) that $t_{N}=8450 \mathrm{~s}$ and $K=2 \times 10^{-4} \mathrm{~m} / \mathrm{s}$.

Displacement of the supporting pipes shifts the previously cool slab-pipe contact sections. As an example, in Fig. 3 (where $X=0$ at the left boundary of the calculated section of slab), we show the temperature variation along the lower surface of a slab (thickness $240 \mathrm{~mm}$ ) for times from 8000 to $10000 \mathrm{~s}$. We clearly see the reduction in temperature heterogeneity over the slab cross section by about half on account of displacement of the supporting pipes. In Fig. 3, $X_{1}$ and $X_{2}$ denote the coordinates of the slab-pipe contact sections before displacement (at $t=8000 \mathrm{~s}$ ) and at the boundary with the monolithic hearth (at $t=10000 \mathrm{~s}$ ). The difference $\Delta X=X_{2}-X_{1}=0.32 \mathrm{~m}$ is the assumed maximum displacement $\Delta S$.

In Fig. 4, we show the time dependence of the temperature of the upper and lower slab surfaces and also the specified temperature of the heating gas $\left(T_{V}\right)$ in the upper zones of the figure. 


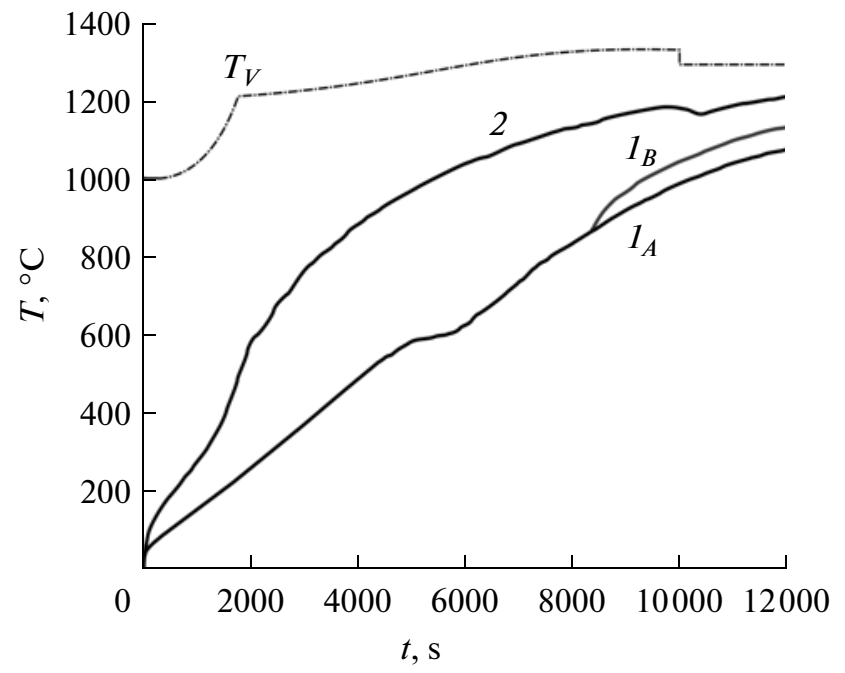

Fig. 4. Time dependence of the temperatures of the lower $\left(1_{A}, 1_{B}\right)$ and upper (2) slab surfaces without $\left(1_{A}\right)$ and with $\left(1_{B}\right)$ pipe displacement: $T_{V}$, temperature of the heating gas in the upper furnace zones.

We see that pipe displacement for $1550 \mathrm{~s}$ very significantly (by $50-60^{\circ} \mathrm{C}$ ) reduces the temperature difference over the cross section $\left(\Delta T=T_{2}-T_{1}\right)$ at the input to the monolithic-hearth zone.

In studying the influence of pipe displacement on the size of the dark spots in the slab, we calculate characteristics of the thermal heterogeneity-specifically, two types of temperature difference: the difference $D_{M}$ in mean-mass temperatures of the metal and the temperature difference $D_{P}$ of the billet's lower surface

$$
D_{M}=\bar{T}_{A}-\bar{T}_{B} ; \quad D_{P}=T_{A B}^{\mathrm{sur}}-T^{\mathrm{sur}},
$$

where $A$ corresponds to the cross section between the supporting pipes and $B$ to the cross section above the supporting pipe.

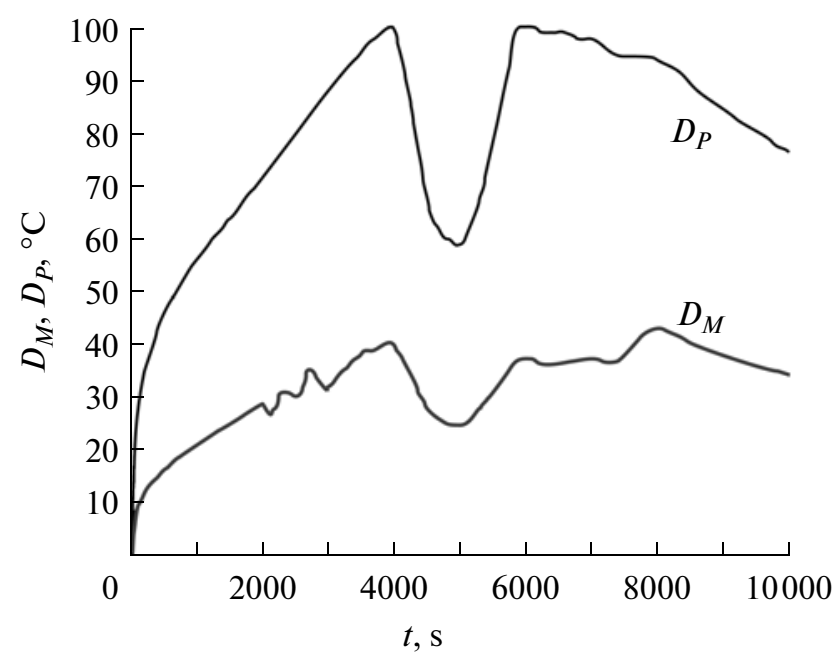

Fig. 5. Time dependence of the slab's thermal heterogeneity without pipe displacement.
In Figs. 5 and 6, we show the time dependence of $D_{M}$ and $D_{P}$ for two states: without pipe displacement; and with pipe displacement when $\Delta S=0.32 \mathrm{~m}, t_{N}=$ $8450 \mathrm{~s}, t_{k}=10000 \mathrm{~s}$, and $K=2 \times 10^{-4} \mathrm{~m} / \mathrm{s}$.

We see that, on slab heating without pipe displacement, the dark spot is relatively large: on entering the monolithic-hearth zone, $D_{P}=76^{\circ} \mathrm{C} ; D_{M}=34^{\circ} \mathrm{C}$.

With pipe displacement, at $t=10000 \mathrm{~s}, D_{P}=15^{\circ} \mathrm{C}$ and $D_{M}=7^{\circ} \mathrm{C}$.

With a furnace productivity of $260 \mathrm{t} / \mathrm{h}$, pipe displacement reduces the difference in mean-mass temperatures of the slab from 33 to $12^{\circ} \mathrm{C}$, as noted in [1]. That is consistent with the calculated $D_{M}$ values.

If the use of the initial displacement parameters in the calculations leads to unsatisfactory thermal heterogeneity of the slab (for example, $D_{P}>60-70^{\circ} \mathrm{C}$ ), we must repeat the calculations with corrected initial parameters $\left(t_{N}, \Delta S, K\right)$. By this means, it is possible to establish the onset of pipe displacement in the furnace and the best displacement parameters.

In addition, the mathematical model may take account not only of the temperature variation of the upper and lower slab surfaces over time but also of the temperature variation at the surface of an insulated pipe, by the method in [7]. Note that, for different heating conditions, the graph of the surface temperature $T_{T}$ of the heat-insulated supporting pipe is practically the same: when the slabs leave the second welding zone, $T_{T}=1000^{\circ} \mathrm{C}$ (Fig. 7).

At present, furnaces for slab heating prior to rolling on broad-strip mills differ greatly in supporting-pipe configuration, especially for stepping-beam continuous furnaces. Judging from the literature, the pipe configuration is selected by purely empirical methods $[4,8]$. Comparison of the cooling properties of the supporting pipes by computer calculations permits

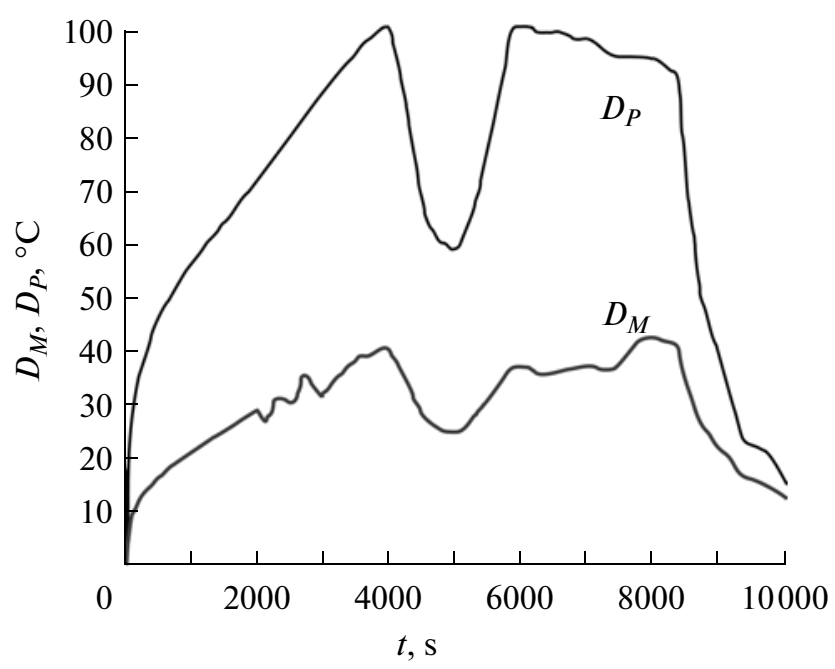

Fig. 6. Time dependence of the slab's thermal heterogeneity with pipe displacement. 


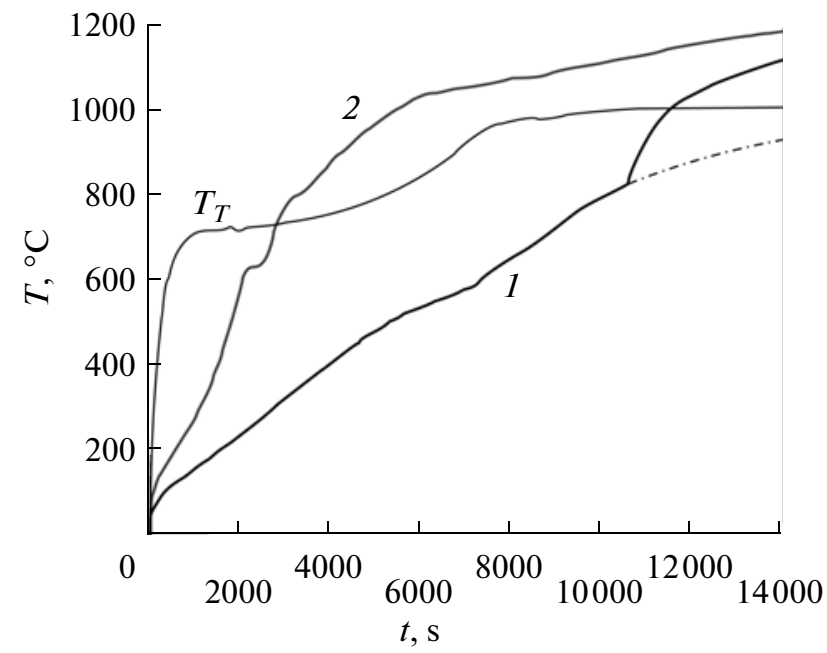

Fig. 7. Time dependence of the temperatures at the lower ( 1$)$ and upper (2) surfaces of the heated slab (thickness $240 \mathrm{~mm}$ ): $T_{T}$, temperature at the surface of the heat-insulated pipe. The dashed curve corresponds to the elimination of the monolithic hearth.

informed choice of the supporting-pipe configuration, with consequent savings in costs and time.

\section{CONCLUSIONS}

We have outlined a method for selecting the best parameters of supporting-pipe displacement in continuous furnaces, with determination of the onset of displacement in the furnace and the maximum possible displacement. By this means, supporting-pipe configurations may be designed for continuous furnaces of push-rod type that differ in size, in productivity, and in the number of longitudinal supporting pipes.

We have studied the influence of the displacement of longitudinal guide pipes in continuous furnaces on the disappearance of dark spots.
We have outlined calculation results reflecting the temperature variation of the upper and lower slab surfaces over time and the temperature variation at the surface of a heat-insulated pipe.

\section{REFERENCES}

1. Bykov, V.V., Frantsenyuk, I.V., Khilkov, V.M., and Shchapov, G.A., Vybor rezhimov nagreva metalla (Selecting the Conditions of Metal Heating), Moscow: Metallurgiya, 1970.

2. Bort, H., Timman, G., and Voigt, H., Chern. Met., 1992, no. 8, pp. 6-13.

3. Makovskii, V.A., Stal', 1961, no. 1, p. 88.

4. Gusovskii, V.L. and Lifshits, A.E., Metodiki rascheta nagrevatel'nykh i termicheskikh pechei (Furnace-Calculation Methods), Moscow: Teplotekhnik, 2004.

5. Samoilovich, Yu.A., Calculation of the Screening of Heated Metal by Guide Pipes, Nagrev $i$ okhlazhdenie stali. Teplotekhnika sloevykh protsessov (Heating and Cooling of Steel: Thermal Engineering of Laminar Processes), Moscow: Metallurgiya, 1970, no. 23.

6. Malikov, Yu.K., Masalovich, V.G., and Vostrogin, A.E., Influence of the supporting-system configuration on slab heating, Sovershenstvovanie elementov $i$ uzlov metallurgicheskikh pechei (Improving the Components of Metallurgical Furnaces), Moscow: Metallurgiya, 1988, pp. 75-82.

7. Budrin, D.V., Calculation of radiant heat transfer, Teploobmen $i$ voprosy ekonomii topliva $v$ metallurgicheskikh pechakh: Tr. UPI (Heat Transfer and Fuel Economy in Metallurgical Furnaces: Proceedings of Ural Polytechnic Institute), Moscow: Metallurgizdat, 1951, pp. 13-37.

8. Gusovskii, V.L., Ladygichev, M.G., and Usachev, A.B., Sovremennye nagrevatel'nye i termicheskie pechi (Modern Furnaces), Moscow: Mashinostroenie, 2001.

Translated by Bernard Gilbert 